\title{
Chaquira, el inka y los blancos: las cuentas de vidrio en los mitos y en el ritual kaxinawa y amerindio*
}

\author{
Els LAGROU \\ Departamento de Antropologia Cultural / Programa de Pós-Graduação em Sociologia e Antropologia, \\ IFCS, Universidade Federal do Rio de Janeiro \\ elagrou@terra.com.br
}

Recibido: 10 de enero de 2013

Aceptado: 24 de enero de 2013

\begin{abstract}
RESUMEN
Este artículo tiene por objetivo mostrar, a partir del análisis del papel de la chaquira en el mito y en el ritual kaxinawa y de su comparación con otros grupos amerindios, cómo este ítem puede permitirnos arrojar nuevas luces sobre temas importantes en la discusión contemporánea de la etnología amerindia, como la importancia dada por los amerindios al «saber hacer» o el conocimiento del origen y el papel de los dueños de las substancias y de los dominios. Otro tema central en la socialidad amerindia es el papel de la incorporación de las fuerzas agentivas de la alteridad en la constitución de la persona. Mostramos que la «captura» de las fuerzas exógenas contenidas en la chaquira sigue una lógica estética local. Por último, el artículo llama la atención sobre el rendimiento teórico de la superposición sistemática de los discursos amerindios que se refieren a los artefactos y a los cuerpos.
\end{abstract}

Palabras clave: Arte indígena, chaquira, kaxinawa, mitología.

\section{Beads, the Inka and the Whites: Glass Beads in Kaxinawa and Amerindian Mythology and Ritual}

\begin{abstract}
In this article we analyse the role played by glass beads in Cashinahua myth and ritual, comparing our results with data on other Amerindian groups and showing how this small item of exchange permits us to discuss themes important for contemporary Amerindian ethnology. First of all we have the Amerindian search for knowledge about fabrication, origin and ownership of the materials they use in daily life and ritual. The role played by the incorporation of the agency of Others in the constitution of the person is central to Amerindian sociality. We show how the «captivation» of the exogenous forces contained in glass beads follows a local aesthetics. Finally we argue for the theoretical interest of indigenous discourses that systematically superpose bodies and artefacts, showing how similar are their inner structure, way of fabrication and agency.
\end{abstract}

Key words: Indigenous art, glass beads, Kaxinawa, mithology

Sumario: 1. Introducción. 2. La chaquira en el mito y en el rito entre los kaxinawa. 3. El caso kaxinawa en el contexto amerindio. 4. Conclusiones. 5. Referencias bibliográficas.

«[...] porque nos tuviesen mucha amistad, porque conoscí que era gente que mejor se libraría y convertiría á nuestra Santa Fe con amor que no por fuerza, les dí á algunos de ellos unos bonetes colorados y unas cuentas de vidrio que se ponían al pescuezo, y otras cosas muchas de poco valor con que hobieron mucho placer y quedaron tanto nuestros que era maravilla. Los cuales después venían á las barcas de los navíos adonde nós estábamos nadando, y nos traían papagayos y hilo de algodón en ovillos y azagayas, y otras cosas muchas, y nos las trocaban por otras cosas que nós les dábamos, como cuentecillas de vidrio y cascabeles» (Relaciones y Cartas de Cristóbal Colón, 1492).

\footnotetext{
* Traducción del portugués de Miguel Carid Naveira y Laura Pérez Gil.
} 


\section{Introducción}

La centralidad de la corporalidad en el proceso de constitución de la persona entre los amerindios se ha convertido en un paradigma en el área de la etnología amerindia ${ }^{1}$, pero las formas en que los artefactos son movilizados en la fabricación de las personas y de los grupos sociales sólo ha recibido una atención más sistemática por parte de los estudiosos de este campo más recientemente. El estudio en profundidad del mundo de los artefactos que participa en la fabricación del cuerpo amerindio arroja nuevas luces sobre los conceptos amerindios de corporalidad y persona ${ }^{2}$. Un aspecto importante de esta relación se refiere a la superposición sistemática de los discursos amerindios relativos a cuerpos y artefactos. Tanto en el caso de la pintura corporal como en el de la decoración del cuerpo con collares de cuentas, dientes y semillas, nos encontramos con el mismo entrelazamiento entre artefacto y cuerpo, entre la fabricación de un cuerpo con capacidad de agencia ${ }^{3}$ y su decoración interior y exterior.

En este artículo nos proponemos abordar esta cuestión a partir de la elaboración, transformación y «pacificación» artística y semántica por parte de los amerindios de los materiales obtenidos a través del contacto con los blancos, más específicamente de la chaquira, las famosas cuentas de vidrio intercambiadas con los viajeros desde las primeras expediciones de los europeos a las Américas. Las chaquiras son verdaderas «perlas de vidrio», expresión que denota la paradoja de la chaquira: es una materia prima preciosa usada en la fabricación de artefactos de alto valor entre la mayor parte de las poblaciones nativas del mundo $\mathrm{y}$, al mismo tiempo, un elemento de trueque entre colonizadores y poblaciones nativas, cuyo valor es objeto de desencuentro entre ambas partes. Los viajantes y colonizadores consideraban que estaban cambiando quincallerías por materias primas preciosas, mientras que los nativos apreciaban mucho estas cuentas de vidrio cuyo modo de producción y origen desconocían ${ }^{4}$. Cuentas de materiales más o menos preciosos, desde el Spondylus rojo y la turquesa hasta las cuentas negras de chonta y blancas de concha, eran usadas mucho antes de la llegada

1 El paradigma de la importancia del discurso sobre la corporalidad para la noción de persona amerindia surge a partir del texto programático, de 1979 [1991], de Da Matta, Seeger y Viveiros de Castro, en respuesta al llamamiento lanzado por Overing, en 1976, para elaborar un tratamiento teórico del material etnológico que supiese sacar provecho de la especificidad del universo indígena amazónico.

2 Precursores en la valorización del mundo de los artefactos y su relación con la construcción de la persona fueron los trabajos de Erikson (1996), Van Velthem (2003), Lagrou (1998; 2007) y Barcelos (2008). El volumen organizado por Santos Granero (2009) reúne investigaciones recientes que tratan esa cuestión, como el trabajo de Steven Hugh-Jones sobre el cuerpo tukano compuesto de artefactos invisibles y el de Joana Miller sobre la relación entre el hilo de cuentas y el alma de la persona. Para un ensayo teórico y comparativo sobre la relación entre personas y artefactos en el mundo amerindio, ver Lagrou (2009).

3 NT: El término agencia es el equivalente del inglés agency, concepto tratado y usado, aunque con ciertas diferencias, por varios autores relevantes de la teoría antropológica contemporánea, como Strathern, Gell o Latour. En general, la agencia hace referencia a la capacidad de acción propia, o de generar la acción de los otros, que varios de los autores entienden a partir de los conceptos de intencionalidad, consciencia y/o creatividad.

${ }^{4}$ En las Américas, la técnica de producción de vidrio era desconocida y las cuentas de vidrio eran recibidas como preciosidades exóticas. Sabemos que uno de los primeros gestos de Colón al llegar al Caribe en 1492 fue el de ofrecer chaquiras a los indios arawak (ver epígrafe). Cien años después, Jean de Léry dará testimonio de la verdadera fascinación que las mujeres tupinambá sentían por las chaquiras llevadas por los franceses (Léry 1975 [1580]: 110-111 apud Schoepf 1976). 
de los blancos. El aprecio de los indígenas por los collares de cuentas hizo que las cuentas de vidrio traídas por los europeos cayeran en suelo fértil ${ }^{5}$.

Se sabe, desde los escritos de Lévi-Strauss y de Clastres (1982), que la mayor parte de las sociedades amerindias sitúa en el exterior su fuente de inspiración artística y cultural. Para los wayana (Van Velthem 2003) y los yekuana (Guss 1989) todos los motivos y técnicas fueron conquistados y robados de enemigos sobrenaturales, sus propietarios originales, y la estética consiste en una traducción estilística: las fuerzas del enemigo son controladas e introducidas a través de una incorporación que los redefine y transforma para que puedan ser puestos al servicio de la sociedad. Vemos aquí una continuidad lógica con el canto del enemigo que canta el homicida entre los araweté (Viveiros de Castro 1986) y el trato dado a la sangre del enemigo que aumenta el poder reproductivo del guerrero wari (Vilaça 1992; Conklin 2001). La sangre del guerrero produce la fertilidad femenina y los dientes de los enemigos yagua garantizan, al igual que las cabezas reducidas jíbaro (Taylor 1985), descendencia al guerrero al mismo tiempo que promueven la fertilidad de las huertas de las mujeres.

La obtención y transformación de los materiales procedentes del exterior en materiales constitutivos de la propia identidad grupal sigue una lógica similar, ya se trate de la incorporación de personas, cualidades o capacidades agentivas de las personas (almas, cantos, nombres) o de objetos. Estos elementos obtenidos del exterior sea a través de la conquista o de la negociación deben ser pacificados, familiarizados ${ }^{6}$. Este proceso de transformación de lo exterior en algo interno tiene aspectos eminentemente estéticos ${ }^{7}$.

Las cuentas constituyen ítems cruciales en el entretejer de caminos entre mundos diferentes y evidencian de forma ejemplar las diferentes formas adoptadas por las poblaciones indígenas para lidiar con la alteridad, a través de una incorporación estilísticamente controlada de ítems procedentes del exterior. La chaquira aparece en gran medida relacionada con los mitos de origen de los blancos, unas veces interpretada como fuente de belleza y riqueza, otras como vehículo y origen de nuevas enfermedades. El discurso mítico y, en algunos casos, los cantos rituales ponen en evidencia la estrecha relación existente entre la actitud frente a los blancos y la actitud frente a la alteridad en general.

Estos aspectos comparativos serán explorados a partir del análisis del material kaxinawa, pueblo de lengua pano que vive en el Acre (Brasil) y en la Amazonía peruana. Entre los kaxinawa la estética y la eficacia ritual consisten en hacer que los

5 Ver, por ejemplo, Dransart (1998) y Meisch (1998) sobre el uso prehispánico de las cuentas en los Andes y en Ecuador, y Graeber (2001) para los Estados Unidos.

${ }^{6}$ La noción de familiarización de mascotas y cautivos entre los amerindios fue elaborada respectivamente por Erikson (1987) y Fausto (1999). En ambos casos se enfatiza una relación de domesticación que implica una relación jerárquica entre el dueño y su «hijo adoptado». En el caso de la pacificación estética en cuestión, sin embargo, más que de subyugar, se trata de seducir a un enemigo poderoso que, provisionalmente y de forma voluntaria, se aviene a prestar su colaboración.

7 Un bello ejemplo de domesticación de los objetos de los blancos aparece en una fotografía tomada por Lux Vidal entre los kayapó-xikrin, donde podemos ver a dos niñas xikrin sujetando una muñeca de plástico. Las muñecas están pintadas, usando genipa, con motivos de la pintura corporal xikrin y ornamentadas con un collar de chaquira. El tratamiento estético dado a la muñeca permitió su transformación en una muñeca xikrin (Vidal 1992). 
«otros», «ex enemigos» -en su mayor parte seres invisibles llamados yuxibu-dueños de las materias primas necesarias para la construcción de un nuevo cuerpo, cedan voluntariamente aquellos ítems que fueron notoriamente negados en los tiempos míticos, lo cual provocó guerras para la conquista de los bienes deseados. La estética es, en ese caso, el operador relacional central que garantiza la eficacia ritual, la cual consiste en la transformación de enemigos en aliados. Es esa transformación la que posibilita la producción de personas a partir de pedazos de artefactos «vivos» que cargan, en su propia constitución, la agencia de otros seres. Dado que los artefactos son producidos para actuar en el marco de la red de intencionalidades humanas de la cual surgieron, constituyen un índice de la misma, el nudo, la cristalización de un campo de fuerzas relacionales que puede ser explorado por medio de un análisis detallado de su materialización ${ }^{8}$.

\section{La chaquira en el mito y en el rito entre los kaxinawa}

«Tía, haz para mí pulseras, brazaletes, tobilleras, cintas para las rodillas $(3 \mathrm{x})$ Exprime la medicina para el dibujo, medicina para el dibujo en mis ojos (2x) Haz mis ojos como cuentas, mis ojos como cuentas $(2 \mathrm{x}) »^{9}$

Canto de Nixpupima, cantado por las mujeres para las neófitas.

Fue en el contexto de la traducción de los cantos nixpupima, rito de paso de los niños y niñas que se encuentran en la fase de cambiar los dientes, cuando las «cuentas de vidrio» llamaron mi atención como elemento de una reflexión nativa sobre la fascinación y la seducción que ejerce el Otro, desde la mítica figura del Inka hasta el actual nawa -el extranjero no indígena-. En los cantos rituales, las cuentas conectan en una cadena de asociaciones conceptos llave como dientes, ojos, semillas, metal, huesos, maíz, kene (dibujo), Inka y yuxin (principio vital, alma, espíritu) (Lagrou 1998).

El nombre del ritual, nixpu pima, significa: «hacerlos comer nixpu», una planta que ennegrece los dientes. Esta intervención marca la etapa final del proceso de preparación de los jóvenes para la participación en las actividades productivas. Después de masticar el nixpu, los niños permanecen recluidos durante varios días hasta el momento de su regreso a la vida normal, marcada por la aplicación del veneno del sapo kampun, que provoca fuertes vómitos cuya finalidad es limpiar el cuerpo del nixpu ingerido. El rito de paso opera una verdadera remodelación del cuerpo con especial atención a los huesos, dientes y ojos del niño. La dieta y los saltos forzados (ixtiu) que anteceden a la aplicación del nixpu tienen por objetivo fortalecer y hacer crecer rápidamente los huesos, mientras que la aplicación del nixpu endurece los dientes. El baño medicinal y las gotas de las plantas medicinales, que son exprimidas en los ojos

8 Nuestra propuesta de tratar los artefactos como nexos de agencias interrelacionadas sigue la de Gell (1998). Con respecto a las afinidades entre la propuesta teórica de Gell y las ontologías amerindias, ver Lagrou (2007, 2009).

9 «Yaya huxe waxunuuun; yaya huxe waxunun eee ee; yaya huxe waxunun; ea kene daun kene dau w(b) etxeswe; ea kene dahun kene dahunwetxeswe hee ee; ea mane beduwa mane beduwawee; ea mane beduwa mane beduwa teka ee hee». 
días antes de la aplicación del nixpu, cuando los niños ya están recluidos y salen del mosquitero solamente en las ocasiones en las que son llevados por los adultos para saltar, sirven para aclarar la visión y la mente, ayudan en el aprendizaje y fortalecen el cuerpo. Es significativo que la palabra mane, en el doble sentido de cuenta y metal, material imperecedero, haya sido invocada para prestar sus cualidades tanto a los ojos como a los huesos y dientes de los niños.

Los dientes son, en muchas sociedades amerindias, el locus de la fuerza vital. Como ejemplo de la asociación, muy difundida, entre dientes y fuerza vital en la Amazonía occidental, podemos citar la costumbre yagua de extraer los dientes de sus enemigos, muertos en guerra, para usarlos como collares. Existe también un mito de este mismo pueblo que describe la humanidad primordial como blanda y frágil por causa de la falta de dientes (Chaumeil 2002).

Según Augusto, especialista ritual que ejecutó el ritual para que yo lo viera y me lo explicó, los dientes poseen yuxin (fuerza vital) y es este yuxin lo que hace que no se rompan. Hombres, mujeres y niños usan los dientes como trofeos de caza como protección y decoración (dau). Niños y mujeres usan los dientes de los monos y roedores para embellecerse y los dientes de cocodrilo para protegerse de las picaduras de serpiente; los hombres guardan los caninos del jaguar en collares con cuentas, como trofeo. Los dientes son usados para hacer collares, alternándose con semillas y cuentas. Los dientes de mono pueden, también, coserse en largas líneas sobre cintas blancas de algodón, que se usan como cinturones, collares, pulseras o adornos para la frente.

Por ser vectores de fuerza vital, los dientes ocupan un lugar de prestigio en la vida social kaxinawa. La única materia prima que puede competir con los dientes es la chaquira. Las mujeres kaxinawa adoran las cuentas y tratan de coleccionar la mayor cantidad posible. Los kaxinawa y la gran mayoría de sus vecinos en Brasil y Perú ven en los antropólogos y en los misioneros una fuente indispensable de estas cuentas que no se encuentran entre las mercancías de los regatones que venden en los ríos y en los mercados locales. Otra manera de obtener chaquira es durante los viajes de los líderes a los grandes centros urbanos de Brasil o del exterior. Si el acceso a las cuentas era bastante difícil en del Acre de los años noventa, esta situación empezó a cambiar recientemente con la introducción en el mercado de la chaquira china, mucho más barata que la checa.

La chaquira blanca, por su asociación con lo imperecedero y por su aspecto de eternamente nuevo, es la preferida, en detrimento de las tradicionales cintas tejidas en algodón (yumen huxe), de entre cinco y diez centímetros de ancho, que se atan alrededor de muñecas, brazos, tobillos y debajo de la rodilla. Estas cintas sustentan las junturas, señalando la estructura ósea (también blanca), que a su vez sustenta el cuerpo, y las articulaciones, que posibilitan el movimiento.

Las articulaciones son, junto con la frente y los ojos, los puntos de intervención en los ritos de curación. Cuando un recién nacido tiene fiebre alta, se exprimirá el jugo de hierbas medicinales primero en su frente, después en los ojos y, finalmente, en cada una de las juntas. Este mismo orden en el procedimiento es seguido cuando se trata de un soplo curativo o masaje. En un mito, la técnica usada para dar vida a un muerto sigue este mismo patrón: se reúnen los huesos, se exprimen plantas medicinales sobre los ojos y las juntas y el héroe, un yuxibu bake (hijo de yuxibu), sopla 
sobre el cráneo y los huesos, invocando al yuxin del ojo para que vuelva al cuerpo. Tan pronto como los huesos son reunidos y humedecidos por el líquido curativo, una nueva piel cubrirá el esqueleto y la persona renace.

En los cantos del rito de paso, la chaquira (mane) aparece como quintaesencia de la dureza y la resistencia. Se pide para los niños dientes y huesos «duros como chaquira», así como ojos blancos, videntes y brillantes, como la chaquira. En el canto ritual, las cuentas son sistemáticamente asociadas a los Inka, dueños de lo imperecedero. Esa asociación los hace, en cuanto categoría social, coincidir con los nawa. Inka y nawa son propietarios de bienes que pertenecen a la civilización urbana. Sus ciudades son hechas de piedra, sus calles son amplias y limpias; son los dueños del metal, del oro, de las chaquiras de colores fuertes y brillantes. En el mito, poseen el fuego y las plantas cultivadas y, en la historia de contacto, poseen el metal, escopetas, cuchillos y máquinas. Su comportamiento con relación a los kaxinawa está caracterizado por la crueldad, la falta de reciprocidad y la avaricia. Son caníbales y comedores de carne cruda. Son la quintaesencia de la alteridad, así como el destino póstumo de todo huni kuin (autodenominación de los kaxinawa que significa «gente verdadera»). Entre sí, sin embargo, su vida es descrita en los mitos como altamente social y organizada. A través de la conjunción con el blanco, la figura del Inka es actualizada.

El modo por medio del cual los mitos y algunos cantos de Txidin (ritual del gavilán) abordan el origen y la manutención de la diferencia étnica, transforma al «otro», al enemigo, en epítome de la alteridad: los muertos. Esta asociación de la alteridad con la muerte se alcanza a través del contraste entre los mundos de lo perecedero y de lo imperecedero. Al asociar a los enemigos con lo imperecedero, los kaxinawa los alejan, cada vez más, de la humanidad. Los Inka, predadores prototípicos, causantes de enfermedades, infligen la muerte y, de cierto modo, se asemejan a la propia muerte por la forma en que manifiestan su poder y su estilo de vida.

La selva se caracteriza por los procesos de crecimiento y debilitamiento, mientras que la vida en las aldeas de los muertos es eterna y circular. La fertilidad de la selva se consigue por medio de la colaboración entre pares complementarios y la «depredación» mutua, al paso que en el mundo de la muerte no hay mutualidad, ya que la muerte nunca da, solamente quita a través de la violencia. Al igual que un jaguar con hambre de carne, la muerte devora lo que puede, voracidad que es ridiculizada en el mito del Inka solitario, quien, al no tener nada más que comer, se devora a sí mismo. La imagen de la voracidad es evocada, también, en la imagen del sol, el fuego del Inka. Por eso, cuando una joven menstrua por primera vez, no debe salir de casa sin la cabeza cubierta: Inka pintsi (el Inka con hambre de carne) puede verla (oler la sangre) y canibalizarla.

El mito de origen de la separación de la humanidad menciona como causa de la migración la búsqueda de mejores tierras, por la mala calidad del barro: todas las ollas que las mujeres hacían se solían romper con facilidad. Por eso, las personas decidieron abandonar la selva y emigrar en dirección a oriente, río abajo (maikidi), en busca de buen barro (piedras y minerales). Al llegar a un gran lago se encontraron con un cocodrilo enorme, cuyo cuerpo atravesaba el lago de un lado a otro. El cocodrilo aceptó dejarlos cruzar pasando por su lomo, pero pidió caza como pago por ello. Todo iba bien hasta el momento en que alguien colocó una cría de cocodrilo en 
su boca. Furioso, el cocodrilo se giró sobre su lomo y el «puente» desapareció. Invadidas por el pánico, las personas se gritaban entre sí. Las que consiguieron atravesar gritaban: «iVe en dirección a los dientes!» (xetadabanã kayuwe!), y las que quedaron al otro lado respondían: «iVe en dirección a las cuentas (de metal)!» (manedabanã kayuwe!). Las que no consiguieron atravesar el lago se convirtieron en los huni kuin, indios que viven en la selva; los que consiguieron atravesarlo se convirtieron en nawa, no indios. Al finalizar el mito, Augusto concluyó: «Los extranjeros son nuestra mitad separada hace mucho tiempo» (nawa kuin nukun bais xateni).

Otro fragmento del mito narra cómo las personas viajaban por la selva y, de repente, se encontraron con un gran árbol, «parecida a la lupuna» (xunu keska), lleno de cuentas de colores. De este árbol crecían cuentas rojas, azules, amarillas y blancas, en gran cantidad. Desgraciadamente, el árbol había sido plantado por el Inka, que lo custodiaba celosamente.

El tema de los caminos que llevan a los dientes y a las cuentas es retomado en los cantos del txidin, rito de iniciación del líder de canto, y en el mito que hace referencia a él. Este mito, llamado manendabanã ('en el camino de la chaquira'), cuenta cómo los deseos encontrados de una pareja, él por los dientes y ella por las cuentas, tiene como consecuencia su separación.

Existen varias versiones de este mito. La primera versión que recogí enfatiza la elección de caminos diferentes. La pareja anda por la selva y en una encrucijada el hombre elige el camino en dirección a la naciente del río y la mujer opta por ir río abajo. La mujer es muy bonita (hawendua txakayamanã). La pareja discute: «Vamos en la dirección de los dientes» (xetandabanã kanuwe!), insiste el marido; la mujer responde: «¡No! Vamos en dirección a la chaquira» (manendabanã kanuwe!). Y así fue, cada uno llamando al otro, cada uno intentando convencer al compañero para cambiar de idea. Pero no sirvió de nada. Cuando Neabu se da cuenta de que ya no escucha la voz de su mujer, desesperado sube al árbol más alto que encuentra y la llama; sin embargo, ya no obtiene ninguna respuesta. La mujer está demasiado lejos y ya no lo escucha. Perturbado, Neabu se cae del árbol y cuando consigue ponerse en pie de nuevo se comporta como un «loco», repitiendo la misma frase todo el tiempo: «jmi mujer, mi mujer, mi mujer! (en ainen, en ainen, en ainen...). No nos detendremos aquí en las peripecias de Neabu, que son narradas con muchos detalles en las diversas versiones que recogí, sino en la llegada de su esposa a la tierra de los Inka.

El mito que me contó recientemente Leôncio Salomão, respetado especialista recién llegado de Perú, cuenta el destino de la mujer:

«Neabu volvió. Y su mujer siguiendo el río, andando por la playa, encontrando a su familia. Pero no fue a su familia a quien encontró, fue al Inka. Venía muy bonita. Cuando buscó y encontró chaquira, fue enfilando la chaquira. Después de enfilar la chaquira, dicen que se puso todos los adornos de chaquira, se pintó toda con chaquira. Se puso todo en el cuerpo. Ató el cuerpo con chaquira. Así se pintó todo con chaquira (con sartas dispuestas verticalmente). Su nombre es: mane tsauani ('se sentó sobre la chaquira'), mane betxia ('encontró chaquira'), mane uinyani ('miró chaquira'). Ella canta que encontró chaquira, todos esos son sus nombres. Este es el canto del txidin».

Después de este relato, Leôncio canta el canto de la chaquira: 


\author{
Mane tsauani \\ mane uinyani \\ inka mane betxia aa \\ inka mane betxia a a \\ inka mane panei \\ mane uiyani \\ inka mane keuin e \\ mane betxia e \\ en kai kai e ee \\ mane tsaua ee \\ en kai kai e ee \\ mane uinyane \\ en kai kai e e
}

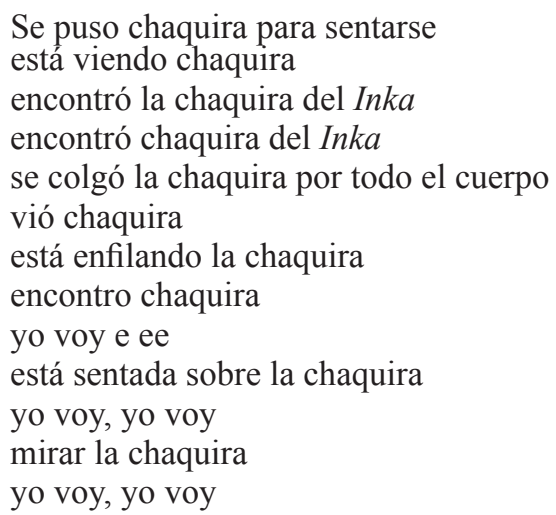

En este momento, se pasa al segundo canto, el canto de manendabanã:
Manen kene manen kene e e e
Inka mane kenei en dakake
Inka mane daui en dakake
Inka mane nexeu en dakake e
Inka mane panai en dakake e e
Inka mane daui en dakake
Dibujo con chaquira, dibujo con chaquira
Estoy pintando con la chaquira del Inka, estoy tumbada
Adorna con chaquira estoy tumbada
Ata toda chaquira estoy tumbada
Con la chaquira colgada por todo el cuer- po estoy tumbada
Con el adorno de chaquira del Inka estoy tumbada

«Apaunibuki: Así se hacía antiguamente. Es así para empezar, antiguamente empezaban a cantar. Yo no sé mucho, pero te voy a explicar para que puedas entender. Sé un poco y voy a enseñarte».
E e e e inka mane kenane ee ee ee Mane kena wanixun
El banco de chaquira del Inka
Hicieron un banco de chaquira
Mane kena tadankin
El banco de chaquira está rodando (como
Tadan tadan baini una bola)
Rueda rápido alejándose

El último canto asocia la chaquira al banco ritual, kenan, hecho de raíces tabulares de la lupuna y destinado a los niños durante el rito de paso. Es estando sentados en el banquito que los niños recibirán la aplicación de nixpu. Este banco es concebido como un modelo reducido del cuerpo del niño (Lagrou 2002, 2007). La idea del modelo reducido del cuerpo está resumida en una de las frases del canto ritual entonado durante la fabricación del banco: «dos piernas con un agujero en medio». Los hombres esculpen el banco en la selva, así como el feto es esculpido en el vientre de la mujer durante el embarazo y, cuando está terminado, las mujeres lo pintan como si fuese un cuerpo. Es interesante notar que en el canto ritual del txidin esta antropomorfización del banco se completa por medio de la decoración con chaquira.

Si la separación transformó a Neabu en una criatura boba y errante, su mujer, al encontrar la chaquira, encontró igualmente a los Inka, lo que equivale a un proceso de volverse otro, extranjera. Su deseo por las cuentas era tan fuerte que la hizo viajar 
sola, abandonando a su marido. Ésta es una interpretación posible; otra, sin embargo, es que ella estaría, en verdad, buscando a sus parientes: el padre de la mujer estaría entre los que consiguieron atravesar el puente del cocodrilo y el motivo real que explica la fascinación de la joven por la chaquira sería el deseo de volver a ver a sus parientes. Leoncia explica, sin embargo, que a quien encuentra no es a sus parientes, sino a los Inka.

Es necesario conquistar los bienes de los Inka y de los nawa, o es necesario pagar un precio, que es el de correr el riesgo de volverse, como la esposa de Neabu, un extranjero. No obstante, los bienes deseados de los extranjeros constituyen, al mismo tiempo, la estructura más interior de la vida social y del cuerpo. Esta consciencia de la presencia constitutiva de la alteridad en lo que es considerado más interior, es el tema recurrente de la mitología de los cantos rituales del Nixpupima y Txidin.

Los kaxinawa demuestran mucho interés en saber cómo se hacen las cosas, quién es su dueño, quién plantó los árboles que producen los frutos que comen y los materiales que utilizan para producir los artefactos. Estas son las preguntas frecuentes que se hacen en relación con los objetos provenientes de las grandes ciudades y con los que traen los visitantes. Se trata de saber cómo y dónde son producidos dichos objetos. Todo objeto es un artefacto y fue, por lo tanto, hecho por alguien. O sea, el artefacto indica una relación.

Las substancias utilizadas poseen una agencia propia que deriva del lazo que las liga de forma permanente a su $i b u$, aquél que las hizo, las engendró. En el rito de paso de los niños y niñas, este saber se revela a través de la utilización constante de cantos que acompañan a las actividades. Todos los ítems utilizados en el moldeamiento de los niños han de ser debidamente cantados para garantizar la presencia de sus dueños: el agua, el maíz, la tinta utilizada para ennegrecer los dientes, la lupuna de donde serán tallados los bancos, las hierbas medicinales con las que los niños serán bañados.

El foco de interés del ritual está en los dientes y en los huesos de los niños. Los huesos deben crecer de forma rápida y vigorosa, como una planta de maíz. Los dientes, endurecerse como un grano de maíz. En la teoría de la concepción kaxinawa, la sangre de la madre formará la carne y la piel del niño, mientras que el semen formará los huesos. Semen y leche materna es lo que sobró del masato de maíz hecho por las mujeres. Lo que queda en el vientre del hombre después de beber masato son las «semillas», el semen del maíz. Se quedan ahí para, más tarde, «convertirse en gente». Cuando son guardadas entre las vigas de la casa se dice que viven en familias, con nombres propios que pertenecen a las mitades.

El canto de las mujeres que bajan al río con las ollas para recoger el agua en que será hervido el maíz revela con claridad esta cadena de asociaciones, donde no sólo los huesos son llamados Inkan mane (cuentas, metal del Inka), y xeki bedu (ojos, semillas de maíz), alimento del Inka que fue robado en los tiempos míticos, sino que el propio maíz es llamado «chaquira del Inka»:

en badiwaka betxia he he he en txana hene betxia

Inka mane itxumaki txanawaka beatãwe Inka mane itxumaki lo encontré en el río del sol encontré el agua del paucar haz saltar la chaquira del Inka Ve y coge agua en el río del paucar Haz saltar la chaquira del Inka 
Como los huesos y el maíz, los ojos y dientes son llamados chaquira, mane, en el canto ritual, pues la intención es pasar sus cualidades de dureza, brillo y durabilidad para estas partes del cuerpo. Vemos así que las cuentas están por todas partes, constituyendo la estructura que sustenta el cuerpo y que lo decora. La chaquira ilustra claramente que, al construir la identidad a través de la traducción y de la incorporación estética de la alteridad, es de crucial importancia que ésta no sea aniquilada. En el caso de los kaxinawa, la agencia de esta alteridad no es ni controlada ni domesticada, como queda claro en los cantos que invocan los dueños de la chaquira, los Inka, sino capturada por medio de un proceso de seducción estética. Todos los dueños de las substancias utilizadas en el ritual son llamados por su canto, su nombre, su diseño, son invitados a la fiesta para alegrarlos, para que colaboren voluntariamente, haciendo que su yuxin permee el producto de su agencia, dándole substancia y vigor. Una tinta que no sea cantada será pálida; una pluma que caiga al suelo, quebradiza.

La estructura interna e invisible, que sustenta el cuerpo y es su parte más duradera, es asociada con el bedu yuxin, el espíritu del ojo. Éste es el único de los espíritus que habitan el cuerpo que posee un destino post mórtem en el cielo, entre los Inka. El canto ritual pretende transformar los huesos, ojos y dientes en chaquira, una chaquira plantada en el cuerpo, como semillas que necesitan echar raíces y crecer como árboles, del mismo modo que el espíritu del ojo fue plantado en el corazón del niño al nacer para allí crear raíces.

Estas semillas, la chaquira del Inka, son chaquiras del enemigo; las mismas o parecidas a las que actualmente se obtienen de los blancos, los nawa. Esta incorporación de substancias y sus cualidades agentivas asociadas a la alteridad, al enemigo, se relaciona con el modelo de depredación amerindio donde el yo es constituido por medio de las capacidades agentivas que se obtienen de fuentes exteriores. A veces la obtención del conocimiento es consentida. Los saberes relacionados con el control del flujo de sangre y con el flujo de imágenes y diseño fueron donados a una vieja kaxinawa por la boa, de la misma forma que lo fueron las cuentas y la pintura corporal de los Inka, con el único inconveniente de que de la tierra del Inka no se puede volver. Llegar al barranco donde viven los Inka y decorarse con su chaquira equivale a asumir su cuerpo y, por lo tanto, a volverse Inka, o sea, morir.

La dialéctica pano de la identidad y la alteridad, con sus mitades englobadas y englobantes, es rebelde a la clasificación que dispone cosas y símbolos en categorías fijas. Si en cuanto destino y filosofía social la figura del Inka es más exterior que la de Yube, la anaconda ancestral, y, por lo tanto, la mitad de los inu asociada con el Inka es más exterior que la de los $d u a$, asociados con la anaconda, en lo que respecta a la ontología los términos se encuentran invertidos: el elemento englobado e interno se vuelve la semilla del Inka, mientras que el englobante es su envoltorio, la piel de Yube, la anaconda. Se puede decir que en el plano de la antropogénesis los humanos son como «hijos» para Yube (porque el líquido y la sangre se originan en el reino de Yube, la anaconda/luna/yuxibu, llamada 'nuestro padre' -nukun ibu-) y afines para el Inka (llamado 'nuestro cuñado' -nukun txai-, con quien el yuxin del ojo se casará después de la muerte). En el plano de la ontogénesis, sin embargo, la relación interior y exterior se invierte: nada es más 'interior', más 'propio', kuin, para un humano que 
sus huesos, sus dientes y el yuxin del ojo. Dado que esos elementos están asociados con el Inka, nada sería considerado más kuin que el propio Inka.

Así, salta a la vista la ambigüedad del concepto Inka, simultáneamente el más «yo» (kuin) y el más «otro» (nawa) de los seres. Inka, máxima alteridad, es también Inka kuin, el destino del yuxin del ojo, lo que quiere decir que a través de la muerte se vuelve tanto 'sí mismo' como 'otro'. En la escatología kaxinawa, la aldea de los muertos es descrita como una aldea al estilo de las de los antepasados (xenipabu). Son el superlativo del ser propio: están totalmente decorados y acumulan todos los dau posibles. El Inka viene a recibir al novato con ropa festiva: la túnica tejida con diseño (tadi keneya), pendientes redondos de concha en las orejas y plumas de arara en las narinas. Como marido de la mujer muerta, la recibe tocando la flauta, un instrumento usado sólo en el contexto de seducción para llamar a la novia. El Inka de la muerte, así, es huni kuin, la cualidad más propia del ser humano.

\section{EI caso kaxinawa en el contexto amerindio}

Es importante llamar la atención sobre la sistemática superposición de discursos relacionados con la producción de artefactos y cuerpos perceptible en el material aquí presentado. Como en el caso de la pintura corporal, en el caso de la decoración del cuerpo con chaquira, dientes y semillas tenemos un intenso entrelazamiento entre artefacto y cuerpo, entre la fabricación interior de un cuerpo vivo y pensante y su decoración exterior. Varias evidencias etnográficas refuerzan esta idea. Así, Van Velthem (2003) muestra cómo las mismas técnicas que hacen el artefacto hacen también el cuerpo humano, y Overing (1991) revela la estrecha relación entre los collares invisibles presentes en el interior del cuerpo y la abundancia de collares de cuentas usados por mujeres con muchos hijos y por poderosos chamanes.

Overing muestra cómo entre los piaroa las cuentas usadas como decoración exteriorizan los poderes productivos, encapsulados en el interior invisible de sus cuerpos. En el cuerpo estos poderes están igualmente almacenados en forma de cuentas, cuentas invisibles, y es el chamán quien busca estas cuentas cargadas de energías y saberes peligrosos durante sus visitas nocturnas y visionarias a las cajas de cristal del cielo, donde habitan los dioses que las poseen. El trabajo del chamán consiste en limpiarlas para que puedan ser usadas solamente para los objetivos constructivos de la vida social, teniendo en cuenta que se originaron de los excrementos envenenados de la anaconda-tapir primordial.

Miller describe un proceso similar entre los maimondê-nambikwara (Miller 2007). Entre los maimondê, el destino de la persona está vinculado a sus cuentas y collares, de tal forma que el hilo de la vida puede ser roto al romperse el hilo del collar que se lleva en el cuello. De este modo, si una mujer no guardó bien sus collares de cuentas puede enfermarse. La cura consiste en una operación chamánica mediante la cual el chamán recupera las cuentas perdidas en el cuerpo de la mujer que las descuidó. El carácter exterior de las cuentas de vidrio queda claro en el caso relatado por la autora. Éstas, a diferencia del propio hilo del collar y de aquellas hechas de coco de chonta 
por los propios maimondê, que son reintroducidas en el cuerpo del paciente, son usadas por la paciente para fabricar un collar para su marido.

También entre los grupos pano existe una relación explícita entre salud, poder y adornos. Entre los shipibo (Colpron 2004), kaxinawa (Lagrou en prensa), sharanahua (Déléhage 2007) y marubo (Cesarino 2008), el chamán recibe sus coronas, collares y diseños invisibles de los maestros cuando éstos le transfieren sus poderes. Para los marubo, los collares de cuentas de concha proporcionan protección a niños, mujeres y hombres. Recientemente, los collares blancos hechos de finos discos de concha pueden ser igualmente hechos con PVC (plástico). Llama la atención que el PVC sufra el mismo proceso en la producción de las cuentas que el caramujo. Las cuentas no llegan ya listas como en el caso de la chaquira. El chamán marubo subraya la diferencia entre los collares de cuentas hechas de PVC y los collares de chaquira. Si los primeros pueden sustituir a los de concha para el uso cotidiano, en relación con los segundos se piensa que pueden producir escozor, 'alergia'. Este ejemplo evidencia la importancia concedida por los indígenas al modo de hacer los adornos en el proceso simultáneo de producción de cuerpos y de adornos ${ }^{10}$. Si para algunos este proceso de «pacificación estética» se refiere al modo por el cual lo discontinuo (la multiplicidad de cuentas) se vuelve continuo (un tejido al estilo nativo hecho con las cuentas), para otros, como es el caso de los marubo, el interés en el hacer incide en la producción de la propia cuenta.

Entre los kaxinawa, por el contrario, lo que viene de fuera es lo que da fuerza y acceso a la curación. El joven informante de Capistrano de Abreu cuenta que conoció al poderoso mukaya (chamán) llamado Yawabiti, que sabía materializar el muka (poder de lo amargo, la substancia chamánica) contenido en su cuerpo de varias formas, entre ellas en forma de chaquira:

«Cuando él (el mukaya Yawabiti) les enseñó su muka, yo los vi. Yo vi los muka que él les mostró: una pequeña bola de veneno, un pequeño pedazo de cuchillo, una pequeña lasca de madera así, él les mostró, y una cuenta, vi todo. (Muka dau tunku mixtin, na nupe teke mixtin, na kadu tumesmixtin hatun uinmaki, na mane hatun uinmaki, keyuwa en uiniki)» (Capistrano de Abreu 1941: 163).

Un mito, llamado Bixku txamiya, versa sobre el poder de curación de los collares y adornos en general. Un convaleciente abandonado a la muerte y cubierto de úlceras escapa del cóndor real que quiere comérselo y le roba sus adornos. La palabra para el adorno es dau, que significa igualmente 'medicina' y veneno. El dau del cóndor real deja a Bixku espléndido, irreconocible. Niños con un problema de enfermedad del alma son decorados con mucha chaquira para protegerlos. Conocí una joven que sufría de lo que, aparentemente, eran ataques epilépticos. Era la niña más decorada de la aldea. Las cuentas, ligadas a los baños medicinales y al rostro pintado con urucú, servían para alejar al doble del animal que estaba intentando llevarla.

El uso de cuentas en este contexto es significativo. Para la cura se buscan sustancias que se relacionan con el poder agentivo del enemigo, en las cuentas está encapsulado su poder. Los huichol (Kindl 2005) y kuna, de la misma forma que los kaxinawa,

10 Comunicación personal de Nilse Marubo durante la investigación desarrollada por la autora en el marco de la preparación del proyecto comparativo 'chaquira'. 
usan la chaquira con fines protectores. Los poderes de los blancos encapsulados en los objetos producidos por ellos no son patogénos en sí. Se gana poder sobre el otro imitándolo, incorporando su poder (Taussig 1993).

Ya entre los desana, los mitos de origen de la viruela y del sarampión cuentan cómo estas enfermedades son la manifestación exterior de las chaquiras que, habiendo sido dadas por las mujeres blancas a las mujeres indígenas, penetraron en su piel y se exteriorizaron en forma de ampollas rojas en su superficie. Aquí el poder contagioso del blanco acompaña a los objetos que emanan de su acción (Buchillet 2000).

Entre los wayana, a su vez, el modo en que la chaquira actúa sobre y en el cuerpo difiere tanto del de los kaxinawa como del de los desana. Lo que resalta es una ambigüedad constitutiva. Es necesario recordar la antigüedad de la presencia maciza de la chaquira en la región de las Guayanas. La red extensa de intercambio entre los indígenas de las Guayanas y los saramaka y boni, negros que habitaban las selvas guayanesas y eran responsables del comercio, llevó a la chaquira desde el comienzo hasta regiones apartadas del convivio inmediato con la vida de las ciudades (Schoepf 1976: 58). Con la chaquira, los indígenas de lengua karib y arawak de la región fabrican desde hace siglos las famosas tangas tejidas con chaquira. La antigüedad de la presencia de estas tangas es atestiguada por Van Velthem y por Schoepf y se remonta al menos al siglo XVII ${ }^{11}$.

Aunque el uso de estas tangas ya no está generalizado entre las mujeres wayana hoy en día, todas las personas wayana, tanto los hombres como las mujeres, usan collares de chaquiras. Se considera que una persona que no esté adornada con sus collares está desnuda, como los monos capuchinos (Van Velthem 2008). Sin embargo, Van Velthem llama la atención hacia el estatuto ambiguo de los artefactos hechos de chaquira. Si de un lado «las cuentas europeas no fueron percibidas por los indígenas como algo completamente desconocido, sino como una fuente de reelaboraciones a partir de un material que ya les era familiar», por otro se nota en el uso actual del material un potencial disyuntivo:

«Los misioneros, católicos y protestantes, con la intención de modificar los diseños de los Amerindios para convertirlos más fácilmente, introdujeron desde el siglo XIX motivos europeos en las Américas. Los indígenas de lengua carib de las Guayanas y del Norte de Brasil reproducen hasta hoy en sus adornos tejidos de chaquira, figuras y escenas con un estilo realista, como perros, helicópteros, flores en jarrones y niños jugando con globos, entre otros, inclusive motivos tradicionales de indígenas norteamericanos. Entre los wayana, los pamila imirikut, 'pinturas corporales de los libros', constituyen una categoría aparte, porque aparecen en los catálogos de bordado que trajeron los misioneros norteamericanos instalados en Surinam a mitades del siglo XX. La reproducción de estos motivos se limita a los adornos hechos con chaquira, lo que refuerza su carácter exógeno. Por otro lado, desde el punto de vista wayana, esta conjunción amplifica los principios ontológicos y expresivos de la alteridad, lo que añade un valor estético al adorno» (Van Velthem 2008: 51-52).

11 «Sous sa nouvelle forme de verroterie, elle (la tanga) est attestée en Guyane française dès 1689» (Schoepf 1976: 57). 
De este modo, los hombres usan cinturones de chaquira con motivos rayados que representan al mismo tiempo el arco iris, un ser sobrenatural, y la bandera de Surinam $^{12}$. Van Velthem habla de «objetos cautivos» (2000) y de la necesidad de domesticar dichos objetos. Los objetos hechos por los wayana son llamados «adornos verdaderos», mientras que los objetos hechos por los blancos son y serán para siempre «falsos adornos», por lo que recibirán un trato diferenciado. Las chaquiras, sin embargo, son los únicos objetos de origen occidental que poseen un mito de origen entre los wayana.

El mito de la «oropéndola que defecaba chaquira» revela que la chaquira posee, en realidad, un origen wayana. Schoepf (1976) analiza el mito, desvelando su intrincada relación tanto con el mundo de los seres invisibles como con el mundo de los blancos. El mito de origen de la chaquira es, al mismo tiempo, la historia de una iniciación chamánica y de un éxodo tan radical que se vuelve un devenir otro, el devenir blanco del protagonista. El mito cuenta las peripecias de un hombre wayana que poseía la capacidad de entender el habla de la lupuna, árbol considerado por los wayana (y por otros grupos de la región, entre los cuales se incluyen los kaxinawa) como «la sede de poderosas fuerzas ocultas emparentadas con las de los chamanes y pajés» (Schoepf 1976: 59).

La lupuna anuncia que se morirá y le pide al hombre que cuide de sus animalitos. «Si cuidas de mis animalitos, serás rico». Cuando el gigantesco árbol se derrumba, el hombre recoge los animalitos para criarlos. Se trata de una oropéndola, un gavilán y un pájaro cancan (oiseau cancan). Después de alimentarlos, todos defecan cuentas, cuentas de varios colores. El hombre guarda los pájaros en un cesto hasta que un vecino curioso los deja escapar. Cuando el dueño consigue capturarlos de vuelta, la oropéndola comenta que ya no quiere vivir en la aldea, que necesita un lugar mayor para vivir, lejos de la aldea. El hombre decide obedecer y seguir a sus crías. Y pasa que anda tan lejos, que llega a Paraná donde funda una ciudad. Es en esta ciudad donde vive hoy la oropéndola que hace cuentas.

A este mito, el narrador Dondon, jefe de la aldea y gran conocedor de la mitología de su pueblo, añade algunos comentarios, actualizando e interpretando el significado del mito. Así, cuenta que hoy en día son los franceses los que recogen las cuentas y que, cuando se retiran muchas cuentas de la oropéndola, se paga inevitablemente con las vidas de varios recolectores de cuentas, los propios franceses que hoy en día controlan la fuente de la chaquira. El narrador informa que un héroe histórico, Mékuanari, fue hasta allí, hasta el mar, y volvió para contar cómo se fabrican y colectan las cuentas hoy en día.

El narrador cuenta igualmente que él mismo ya encontró, dos veces, una oropéndola que hacía chaquira. En una ocasión, mató una y encontró chaquira en su vientre; en otra ocasión, la hirió con una flecha. Cuando la recogió, aún viva, pudo ver que el pájaro defecaba cuentas. El pájaro, sin embargo, se escapó y murió poco tiempo después de haber sido capturado (Schoepf 1976: 61-66).

La resonancia entre el mito wayana de origen de la chaquira y el mito kaxinawa salta a la vista. Ambos mitos y sus actualizaciones en los rituales y/o en lo cotidiano se refieren a tres problemas entrelazados que me parecen resumir bien el interés que

12 En el Xingú, de la misma forma que entre los kayapó, nos topamos con la omnipresencia de banderas y símbolos de equipos de fútbol en los cinturones -en el caso de los primeros-y en los brazaletes -en el caso de los segundos-, lo que parece sugerir una lógica similar a aquella operativa entre los wayana. 
tiene la chaquira para la etnología amerindia: el origen exógeno de muchos saberes, técnicas y materiales necesarios para la fabricación y decoración de los cuerpos; la problemática de la pérdida de un saber que ya fue endógeno; y la importancia de las técnicas de producción, del hacer, en la transformación de materiales exógenos en artefactos y cuerpos «propios».

Schoepf demuestra que los wayana se interesan por el propio proceso de fabricación de la chaquira, y que el mito pretende mostrar que la chaquira era originalmente un artefacto resultante de un saber hacer propiamente wayana. Se trata de la unión entre un poder sobrenatural -los «animalitos» de la lupuna mantienen una relación metonímica con el poder chamánico de esta- y un alimento doblemente humanizado: sólo después de recibir el ñame cocinado de su nuevo dueño, la oropéndola empezará a defecar chaquira. El ñame es una planta cultivada que recibe el tratamiento transformador de la cocción. Tenemos, de esta forma, la conjunción de tres fuerzas agentivas: la del antiguo dueño, la lupuna, que continua actuante en su cría; la del nuevo dueño y sus técnicas humanas de transformación (el plantío y la cocción); y la de la oropéndola que ingiere y digiere el alimento transformándolo en cuentas preciosas.

Vale la pena recordar que el mito piaroa que narra el origen de las cuentas, procedente de la misma región de las Guayanas, asocia igualmente cuentas y excreciones. Como vimos, en este mito las cuentas negras, hechas de una piedra aluvial, tienen como único dueño al poderoso ser sobrenatural, la anaconda-tapir.

El mito wayana de origen de la chaquira continúa, sin embargo, contando cómo los wayana perdieron este saber. De la misma forma que en el mito kaxinawa de la separación de la humanidad entre huni kuin-indios, habitantes de la selva- y nawa -blancos, habitantes de la ciudad-, el desenlace se debe a un error aparentemente insignificante. Desde el punto de vista de los ofendidos, sin embargo, se trata de verdaderos ultrajes: matar a un pariente del cocodrilo, en el primer caso, y revolver en la propiedad privada del dueño de la oropéndola, en el segundo. La impresión que queda, no obstante, es que la causa no se corresponde con las consecuencias irreversibles que siguen al error. El mismo tema resurge en los mitos que cuentan el origen de la vida breve: en la versión kaxinawa, una persona no oye el consejo de su abuelo de cambiar la piel y por eso la humanidad muere para siempre.

Todos estos mitos tienen en común la cuestión de que antes el mundo no estaba dividido entre los que mueren y los que viven eternamente, entre los que poseen alta tecnología y los que andan sólo con arco y flecha, o, para volver a nuestro tema, entre los que saben hacer chaquira y los que ya no saben hacerla.

En ambos mitos de origen de la chaquira, el de los wayana y el de los kaxinawa, notamos el mismo tema: la chaquira sugiere la búsqueda de un rencuentro. Los Inka, o ahora los blancos, aquellos que habitan al otro lado del gran agua que separó a los indios de los otros, son «nuestra mitad partida», son aquellos huni kuin antiguos que se marcharon, atravesaron el puente del cocodrilo y acabaron convirtiéndose en los blancos. La mujer que va buscando la chaquira está, en realidad, queriendo reencontrar a sus parientes, a su padre. Sin embargo, lo que ella encuentra al hallar la fuente de la chaquira es a los Inka. 
Como sucede en los mitos de otros pueblos indígenas de la región, como los kayapó y los tiriyó ${ }^{13}$, el mito kaxinawa considera la chaquira más como una semilla que como un artefacto. Todos estos mitos remiten a un gran árbol, que antiguamente sabían encontrar, donde crecía todo tipo de chaquiras que ya estaban listas para ser usadas. El mito wayana, sin embargo, evidencia una preocupación por saber cómo son hechas las cuentas, lo que subraya la ambigüedad de la chaquira, a medio camino entre el interior y el exterior, por el hecho de haber sido fabricada a través de la reunión de agencias pertenecientes a diferentes dominios del cosmos. Aun así, la chaquira no es para los wayana un artefacto en sí. Aún no es un adorno, sino la materia prima a partir de la cual se producen los artefactos: artefactos quiméricos que decoran el cuerpo al modo indígena, o sea, que completan el cuerpo con collares en vez de cubrirlo con ropas.

Para los huicholes mexicanos el origen exógeno de la chaquira no parece constituir ningún problema. En vez de elaborar en el mito, como en el caso kaxinawa y wayana, su posición ambivalente entre el interior y el exterior, el mito declara que la chaquira siempre fue la expresión de lo más propio entre lo que existe para los huicholes, ya que el ancestral Kuka Temai (el joven hombre chaquira) es uno de los héroes creadores de su universo, el primero que realizó el viaje iniciático a Wirikuta, tierra del peyote, hongo sagrado para los huicholes, que al ser ingerido produce visiones. Para los huicholes, la cuenta de vidrio significa vida. Al nacer un niño, una parte de la persona viva, llamada 'cuenta' (tauka), se queda en el cielo. Esta cuenta se reseca cuando la persona muere (Preuss 1998 [1908]: 285; apud Kindl 2005: 257). Las cuentas son igualmente identificadas con los granos de maíz y con las gotas de agua (ibid.).

Como vimos antes, en la trascripción del canto, también para los kaxinawa la chaquira está asociada con las cualidades de durabilidad, brillo, claridad y vida duradera, cualidades éstas que las niñas piden en la música ritual del nixpupima para sus ojos, para su visión. La visión pertenece al bedu yuxin, espíritu del ojo, que reside en el corazón y posee su origen y destino celestial entre los Inka.

El análisis de los cantos anteriormente transcritos nos muestra que la significación de la chaquira en la vida amerindia va más allá de la metáfora del trofeo de guerra; apunta más bien a la idea de pacificación, seducción, relación. Como ya mencionaron Cristóbal Colón y Jean de Léry, las cuentas se dan para evitar la guerra, para conquistar el amor de las mujeres indígenas.

Para ilustrar esta idea, vale la pena considerar otro artefacto, además de las hileras de cuentas blancas que se atan en las articulaciones, producidas con chaquira por las mujeres kaxinawa. Se trata de pulseras y collares tejidos formando diseños. Este arte del tejido con chaquira es de origen más reciente. La pulsera de chaquira coexistía en el río Purús con las pulseras tejidas con algodón, que igualmente exhiben diseños. Las mujeres hacían estas pulseras con motivos provenientes del stock tradicional usados en los tejidos (kene kuin) y eran regaladas a novios, maridos o amantes. Hasta hace poco tiempo este tipo de pulseras no era comercializado. Actualmente, en el río Jordão, se vive una explosión en la producción de artefactos de varios tipos hechos con chaquira, desde collares y diademas hasta bolsas y mochilas.

13 Comunicación personal de André Dermarchi que investiga esa temática entre los kayapó, mebengokrê, y de Denise Fajardo, que trabaja con los tiriyó. 
El tema de los hilos o diseños tejidos con chaquira como caminos que ligan mundos distintos ${ }^{14}$ remite a la materialización de los lazos que, hoy en día, los kaxinawa establecen con las varias caras de la alteridad, incluido el fenómeno de las fronteras permeables entre grupos y personas en constante movimiento y «estar entre»: personas que, sin embargo, no se olvidan de la importancia que tiene tejer caminos, hacer nudos y retornar por los mismos caminos que vinieron.

En ese sentido, las pulseras tejidas con chaquira son artefactos esencialmente relacionales, crean puentes entre mundos, entre los jóvenes que las usan, y que a veces proporcionan la propia materia prima, y las jóvenes que las hacen, y que proveen su saber sobre el diseño y la técnica. Estos emblemas de relación amorosa ligan los mundos por los cuales circulan los jóvenes líderes: el mundo de los viajes y las ciudades distantes, de donde viene la chaquira, y el mundo de la aldea, a donde siempre retornan.

Los motivos tejidos por las mujeres, a su vez, son considerados la «escritura de los yuxin» y remiten al encuentro secreto de la mujer que pintaba con la boa ancestral, dueña de los diseños. Es decir, tanto por parte de los hombres que proporcionan la materia prima, como por parte de las mujeres que fabrican las pulseras, éstas remiten a relaciones con un mundo que está más allá del mundo indígena, las cuales tienen profundos efectos sobre el mundo interno de las relaciones del parentesco. También aquí, como en el caso de los jívaro, vemos operativa una lógica de la visibilidad y el ocultamiento de relaciones con el mundo humano y no humano que constituyen el sentido del yo de una persona (Taylor 2003).

Del mismo modo que el dibujo actúa estableciendo relaciones entre cuerpos y personas, como filtro y malla protectora en el cuerpo, guía en el mundo de las visiones o trampa del alma en los sueños, los hilos de la chaquira actúan sobre el mundo social, objetivando o volviendo visibles las redes de relaciones. El acceso a la memoria social, activado por estas imágenes-signos (Severi 2003), se da a partir de los cantos vinculados con los contextos en los cuales los diseños y las cuentas actúan.

\section{Conclusiones}

En la introducción al catálogo Iconoclash, Latour muestra cómo la civilización occidental tuvo desde sus orígenes problemas con la figura de la mediación: cuando «la mano que produce» las imágenes se hace visible, la veracidad de la revelación, sea religiosa o científica, es cuestionada. Una paradoja se hace evidente: «o haces o eres hecho». La búsqueda del acceso no mediado a Dios o a la verdad es el motor de la historia religiosa europea. ¿Cómo se puede revelar la mano humana presente en la fabricación del ídolo y al mismo tiempo afirmar que el ídolo es dios? (Latour 2002).

Los amerindios no están interesados, en lo más mínimo, en eliminar la mano que hace; al contrario, lo que este artículo ha pretendido mostrar es que ellos prefieren multiplicar en vez de ocultar esas manos mediadoras, mostrando que todo producto, sea un artefacto o un ser humano, es el resultado de múltiples mediaciones y rela-

\footnotetext{
14 Analizo en otro texto la concepción kaxinawa de los diseños como caminos que unen mundos (Lagrou $2007,2011)$ y que permiten el pasaje y la transformación de la percepción del mundo visible para el visionario.
} 
ciones. La problemática que induce a la iconoclasia europea no se plantea aquí. En vez de la cuestión de saber si el ícono es o no es un ídolo, lo que aquí importa es la cuestión de la indexicalidad.

Esta es la característica que más fascinaba a Lévi-Strauss del arte que él consideraba como gran arte, y que podría ser encontrada tanto en los maestros del Renacimiento como entre los escultores de la Costa Noroeste de los EE.UU. En el primer capítulo de El pensamiento salvaje leemos que para haber arte tiene que existir «resistencia»: es necesario ver la mano del artista luchando contra la resistencia de la materia o contra la irrepresentabilidad de lo invisible. La visibilidad de la mediación humana en el origen del artefacto representa para Lévi-Strauss la fuerza de la obra de arte premoderna.

Lo que nos interesa retener aquí de la contribución lévi-straussiana al debate sobre la agencia de los artefactos entre los amerindios es esta idea del hacer, de la mano del artista o del hechicero que hace. Como también registró Taussig (1993), cuanto más se revelan los trucos necesarios para invitar a los dioses a la ceremonia, tanto más fuerte es la certeza de que las divinidades se encontrarán presentes en ella.

Este artículo ha intentado mostrar, a partir del análisis del papel de la chaquira en el mito y en el rito kaxinawa y su comparación con datos de otros grupos amerindios, cómo este ítem puede permitirnos arrojar nuevas luces sobre temas importantes en la discusión contemporánea de la etnología amerindia.

En primer lugar, la importancia dada por los amerindios al «saber hacer». Esta cuestión está vinculada con el conocimiento del origen y el rol de los dueños de las substancias y de los dominios ${ }^{15}$, llamados $i b u$ por los kaxinawa. Es necesario saber quién los fabricó, plantó o engendró, quién se encarga de determinada substancia para poder usarla sin riesgo. Como mostramos, el rito de paso consiste en llamar a los dueños de todas las substancias utilizadas en el ritual para garantizar la presencia de las cualidades del material utilizado que se quiere pasar a los pequeños. Si en el mito estas cualidades y el saber cómo reproducirlas eran conquistadas del enemigo avaro, la técnica ritual consiste en invitar a los dueños y seducirlos para que colaboren. Esto se hace no a través de la subyugación, sino a través de la entonación del canto del dueño, alegrándolo. Es de este modo que durante el ritual del nixpupima el líder del canto se vuelve el propio Inka, cantando en su nombre, vistiendo su ropa y su dau.

Otro tema central para la socialidad amerindia es el papel de incorporación de las fuerzas agentivas de la alteridad en la constitución de la persona. La chaquira pasa de ser sólo un trofeo a transformarse en fuerza exógena encapsulada que viene a ayudar en la constitución del cuerpo de los niños. Este artículo ha querido mostrar cómo esta «captura» de las fuerzas exógenas contenidas en la chaquira sigue una lógica estética: una multiplicidad de pequeñas partículas discontinuas es trasformada en un tejido o una hilera continua de colores y motivos que siguen la lógica estilística local. El trabajo de encapsulamiento, sin embargo, es también ritual. Como vimos, los cantos del nixpupima pretenden «alegrar» a su dueño principal, el Inka, es decir, hacerlo presente en la materia.

15 Para una reflexión sobre el tema de los Dueños en la Amazonía ver Fausto (2008). 
Como examinamos en las anteriores páginas, el tema de la «vida breve», estudiado por Lévi-Strauss en las Mitológicas, está también presente en la mitología que trata de la chaquira. De la misma manera que los mitos de origen de la muerte versan sobre un tiempo en el que dioses y humanos vivían en continuidad y los muertos podían volver a la vida, los mitos sobre el origen de la chaquira hablan de un tiempo en el que la chaquira era «nuestra». Esta temática es explícita en el mito wayana de la oropéndola que defecaba chaquira, pero se encuentra igualmente entre los kaxinawa. La fascinación por los materiales imperecederos posee una relación clara con el tema mítico del origen de la muerte, así como con el origen de la separación de los humanos entre indios y no indios.

Finalmente, llamamos la atención sobre el desempeño teórico de la superposición sistemática de los discursos amerindios que versan sobre artefactos y cuerpos. Esta superposición sugiere una concepción del mundo donde no existe Naturaleza. Porque todo fue fabricado, plantado y cuidado por alguien, todo es producto del pensamiento (Overing 1991) y del hacer de alguien. Por esta razón no existe creación ex nihilo (Viveiros de Castro 2002), ni de cuerpos ni de artefactos. Toda fabricación es un bricolaje, el lugar de encuentro de relaciones materializadas en las substancias utilizadas.

\section{Referencias bibliográficas}

Barcelos Neto, Aristóteles

2008 Apapaatai: rituais de máscaras do Alto Xingu. São Paulo: EDUSP.

Buchillet, Dominique

2000 Contas de vidro, enfeites de branco e 'potes de malária'. Epidemiologia e representações de doenças infecciosas entre os Desana do Alto Rio Negro. São Paulo: Ed. da UNESP - Imprensa Oficial do Estado.

CAPISTRANo De ABReu, João

1941 Rã-txa hu-ni-ku-ĩ : a lingua dos caxinauás do Rio Ibuaçu affluente do Muru (Prefeitura de Taranacá). Río de Janeiro: Sociedade Capistrano de Abreu.

Cesarino, Pedro

2008 A poética da morte e do mundo entre os Marubo da Amazônia ocidental. Tesis de Doctorado, Universidade Federal do Rio de Janeiro.

Clastres, Pierre

1982 Arqueologia da violência: Ensaio de antropologia política. São Paulo: Brasiliense.

Colpron, Anne-Marie

2004 Dichotomies sexuelles dans l'étude du chamanisme: le contre exemple des femmes «chamanes» shipibo-conibo (Amazonie Péruvienne). Tesis de Doctorado, Université de Montréal.

ConkLin, Beth A.

2001 «Women's Blood, Warriors' Blood, and the conquest of vitality in Amazonia», en Gender in Amazonia and Melanesia. An exploration of the Comparative Method, Thomas Gregor y Donald Tuzin, eds., pp. 141-174. Berkeley: University of California Press. 
Chaumeil, Jean-Pierre

2002 «Armados hasta los dientes. Los trofeos de dientes humanos en la Amazonía», en Artefacts and Society in Amazonia, Thomas Myers y Maria Susana Cipolletti, eds., pp. 115-126. Bonn: Verlag Anton Saurwein.

Dransart, Penny

1998 "A Short History of Rosaries in the Andes», en Beads and Bead Makers. Gender, Material Culture and Meaning, Lídia D. Sciama y Joanne B. Eicher, eds., pp. 129146. Oxford: Berg.

ERIKSON, Philippe

1987 «De l'apprivoisement a l'approvisionnement: chasse, alliance e familiarisation en Amazonie amérindienne». Techniques et Cultures 9: 105-140.

1996 La Griffe des Aïeux. Marquage du corps et démarquage ethnique chez les Matis d'Amazonie. París: Editions Peeters.

Fausto, Carlos

1999 «Of Enemies and Pets: Warfare and Shamanism in Amazonia». American Ethnologist 26 (4): 933-956.

2008 «Donos demais: maestria e domínio na Amazônia». Mana 14 (2): 329-366.

GELL, Alfred

1998 Art and Agency. An Anthropological Theory. Oxford: Clarendon Press.

GRAEBER, David

2001 Toward an Anthropological Theory of Value. Nueva York: Palgrave.

Guss, David

1989 To Weave and Sing. Art, Symbol and Narrative in the South American Rain Forest. Berkeley: University of California Press.

KINDL, Olivia

2005 «L'art du nierika chez les Huichol du Mexique. Un 'instrument pous voir'», en Les cultures à l'œure. Rencontres en art, pp. 225-248. París: Éditions de la Maison des Sciences de l'Homme.

LAGROU, Els

1998 Cashinahua Cosmovision: A Perspectival Approach to Identity and Alterity. Tesis de Doctorado, University of St. Andrews.

2002 «Kenan, the Ritual Stool: A Reduced Model of the Cashinahua Person During the Nixpupima Rite of Passage», en Artifacts and Society in Amazonia, Thomas Myers y Maria Susana Cipolleti, eds., pp. 95-113. Bonn: Verlag Anton Saurwein.

2007 A fluidez da forma: arte, alteridade e agência em uma sociedade amazônica [Kaxinawa, Acre]. Río de Janeiro: Topbooks.

2009 Arte indígena no Brasil: agência, alteridade e relação. Belo Horizonte: C/Arte.

LATOUR, Bruno

2002 «What is Iconoclash?», en Iconoclash, Bruno Latour y Peter Weibel, eds., pp. 1639. Karlsruhe - Cambridge: ZKM - MIT Press.

MeIsch, Lynn A.

1998 «Why Do They Like Red? Beads, Ethnicity and Gender in Ecuador», en Beads and Bead Makers. Gender, Material Culture and Meaning, Lídia D. Sciama y Joanne B. Eicher, eds., pp. 147-175. Oxford: Berg. 
Miller, Joana

2007 As coisas. Os enfeites corporais e a noção de pessoa entre os Mamaindê (Nambiquara). Tesis de Doctorado, Universidade Federal do Rio de Janeiro.

OVERING, Joanna

1991 «A estética da produção: o senso da comunidade entre os Cubeo e os Piaroa». Revista de Antropologia 34: 7-33.

Santos-Granero, Fernando, ed.

2009 The Occult Life of Things: Native Amazonian Theories of Materiality and Personhood. Tucson: The University of Arizona Press.

SchoEPF, Daniel

1976 «Le japu faiseur de perles: un mythe des indiens Wayana-Aparai du Brésil». Bulletin Annuel du Musée d'Ethnographie de Genève 19: 55-82.

Severi, Carlo

2003 «Warbug anthropologue ou le déchiffrement d'une utopie». L'Homme 165: 77-128.

TAussig, Michael

1993 Mimesis and Alteriry. A Particular History of Senses. Nueva York: Routledge.

TAYLOR, Anne-Christine

1985 «L'Art de la réduction. La guerre et les mécanismes de la différenciation tribale dans l'ensemble Jivaro». Journal de la Société des Américanistes 71: 159-189.

2003 «Les masques de la mémoire. Essai sur la fonction des peintures corporelles jivaro». L'Homme 165: 223-248.

VAN Velthem, Lucia

2000 «'Feito por inimigos’. Os brancos e seus bens nas representações Wayana do contato», en Pacificando o Branco. Cosmologias do contato no Norte-Amazônico, Bruce Albert y Alcida R. Ramos, eds., pp. 61-84. São Paulo: Ed. da UNESP - Imprensa Oficial do Estado.

2003 O Belo e a Fera. A estética da produção e da predação entre os Wayana. Lisboa: Assirio \& Alvim - Museu Nacional de Etnologia.

2008 «Des perles de verre: deux mondes en interaction», en Planète mètisse, Serge Gruzinski, ed., pp. 50-55. París: Musée du Quai Branly.

VIDAL, LuX

1992 «A pintura corporal e a arte gráfica entre os Kayapó-Xikrin do Cateté», en Grafismo Indígena. Estudos de Antropologia estética, Lux Vidal, ed., pp. 143-189. São Paulo: Studio Nobel - FAPESP - EDUSP.

VILAÇA, Aparecida

1992 Comendo como gente. Río de Janeiro: Editora UFRJ - ANPOCS.

Viveiros De Castro, Eduardo

1986 Araweté, os deuses canibais. Río de Janeiro: Jorge Zahar-ANPOCS.

2002 A inconstancia da alma selvagem. São Paulo: Cosac Naify. 